Available online at www.jmle.org

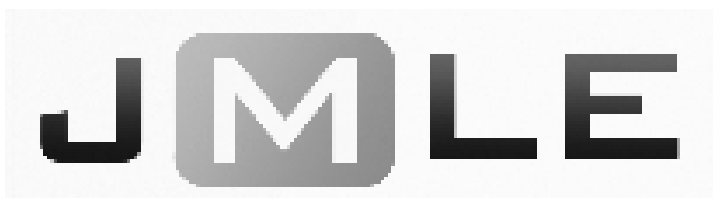

The National Association for Media Literacy Education's

Journal of Media Literacy Education 10 (3), 43 - 56

\title{
Media Literacy and Response to Terror News
}

\author{
Daniel Bergan \\ Heysung Lee \\ Michigan State University
}

\begin{abstract}
Increased fear and threat toward terrorism in the current American society is largely due to vivid news coverages, as explained by cultivation theory and mean world syndrome. Media literacy has potential to reduce this perception of fear and threat, such as people high on media literacy will be less likely to be affected by terror news. We focus on representation and reality for investigating the relationship between influence of terror news and media literacy, one component of media literacy framework developed by Primack and Hobbs (2006), which deals with how media messages represent reality. Our study divided participants into two groups, reading terror news or another news without any threat, and measured their levels of media literacy. The results show that media literacy does not reduce the influence of terror news. More solid theory of media literacy is needed in order to resolve this impasse and explain impact of media use on perception of hazardous world.
\end{abstract}

Keywords: media literacy, news, terrorism, mass communication

Since the 9/11 terror attacks, Americans have felt threatened by terrorism (Norris, Kern, \& Just, 2003). Polling shows that about half (48\%) of Americans worry about terror attacks in the U.S. (Gallup, 2016). However, terrorist attacks have actually declined around the world, and terror attacks tend to be concentrated in the Middle East, not North America, according to U.S. State Department (2015). The discrepancy between the perception and reality may stem from individuals' exposure to media coverage of terrorism. According to proponents of the mean world syndrome, heavy media consumption results in exposure to violent media coverage, in turn influencing perceptions of the world as hazardous (Gerbner \& Gross, 1976).

How can people resist the influence of scary media stories on fear and risk perceptions? Media literacy is an emerging concept which could potentially 
explain differential responses to the influence of news reports on biased perceptions of threats, as well as understanding how education in media literacy could help people to resist the influence of unusual but vivid stories about terrorism, crime, and disasters. Media literacy refers to the ability to access, evaluate, analyze, and create media contents (Ashley, Maksl \& Craft, 2013). Some prior work deals with different topics, but is nonetheless promising, demonstrating the influence of media literacy education on media use. Previous research has shown that media literacy education can influence perceptions of media bias (Vraga et al., 2009) and critical thinking toward media violence (Scharrer, 2006).

In this paper, we are in particular interested in a subset of media literacy content. Primack and Hobbs (2006) explicate multiple components of media literacy, including authors and audience, messages and meanings, and representation and reality. We in particular are interested in literacy about representation and reality, which concerns how media messages represent or omit values or viewpoints of reality (Primack \& Hobbs, 2006). We argue that people high on this component of media literacy will be more likely to recognize that scary news stories are not representative of events in the world, and will therefore be less likely to be influenced by them.

The first section summarizes the literature on cultivation theory and the mean world syndrome, according to which people exposed to news coverage become more fearful of threats. We summarize the recent literature on media literacy, which has shown to have a number of effects on media consumption and attitudes about media. We argue that representation and reality, a specific component of media literacy, shows great promise in limiting the effect of news stories on fear and perceptions of risks, as people high in this component will be likely to recognize that scary news stories are not representative of events in the world. The second section discusses the design and measures of our online experiment. We develop a valid and reliable scale based on prior work on the representation and reality component of media literacy. The third section summarizes the results. We do not find that media literacy reduces the impact of scary media stories, and may even increase their effect on concerns about terror. The fourth section includes a discussion of the meaning of the results for research on media literacy. We conclude with some caveats and directions for future research.

\section{LITERATURE REVIEW}

Media literacy and media literacy education have received increasing levels of attention from scholars in recent years (Kellner, \& Share, 2005). Center for Media Literacy defines media literacy as an ability to access, analyze, evaluate, and create messages in a variety of forms. Several core concepts in media literacy are: (1) All media messages are 'constructed': media messages are selected and made by a few people, who standardize reality (2) Media messages are constructed using a creative language with its own rules: each type of media, like 
$\mathrm{TV}$, radio, or music, use different techniques to convey a message using distinctive tools like sounds, visuals, and metaphor systems. (3) Different people experience the same media message differently: individuals interpret the media message based on their life experience like age, gender, education, etc. (4) media have embedded values and points of view: media uses specific characters and plots to show attitudes or behaviors of certain values. (5) Most media messages are organized to gain profit and/or power: the major object of media industry is to make profits by getting more consumers then selling more advertisements (Thoman, \& Jolls, 2006).

Media literacy informs how citizens understand the process and tactics of journalism in order to enable critical thinking toward news and media (Vraga, Tully, Akin \& Rojas, 2012). Prior work has provided evidence that media literacy education can influence critical media use. For example, Eintraub, Kristine and Johnson (1997) investigated effects of media literacy education on children's perceptions and behaviors of alcohol advertisement. Third graders educated in media literacy had a better understanding of alcohol advertising than children without not educated in media literacy. Media literacy training decreases children's desires to be like the characters in advertisements, purchase advertized products, and, most relevant to the current paper, made children less likely to accept television representations as reality. Scharrer (2006) found that $6^{\text {th }}$ graders in public school were more likely to think critically about violence portrayed in media after taking media literacy programs.

Media literacy could be particularly influential in addressing perceptions of media portrayals as accurate depictions of reality. This is particular true for portrayals of unusual but vivid events such as crimes, terrorism, and disasters (Combs \& Slovic, 1979; Darling-Hammond, 2016). Scholars have seized on this biased coverage of crime and other unusual events, arguing that exposure to news and entertainment coverage of violence and other unusual events can influence perceptions of the world (Morgan \& Shanahan, 1997; Romer, Jamieson, \& Aday, 2003).

Primack and Hobbs (2006) developed a media literacy framework, which is consisted of authors and audience, messages and meanings, and representation and reality, based on previous researches on media literacy. The scale was initially developed for smoking media literacy, but it is positively related to general media literacy scale (Bier, Schmidt, Shields, Zwarun, Sherblom, Primack, Pulley \& Rucker, 2013) and news media literacy scale (Ashely et al., 2013). Some scholars of media literacy have focused on representation and reality as an important component of media literacy. Gainer (2010) emphasizes that understanding representation politics in media is crucial to counter sensational media messages. Also, representation and reality is imperative in that distorted images of the world on media can reinforce stereotypes and marginalize minorities (Fürsich, 2010) and blur the distinction between the news stories and 
reality (Bennett, 2015). In this sense, among three components in media literacy, it is plausible that representation and reality would be associated with perception and risk of terrorism after exposing to terror news. In prior work on developing scales to measure media literacy, representation and reality, the concept is measured with two items (1) messages filter reality (2) messages omit information (Primack \& Hobbs, 2006).

\section{Hypotheses}

Evidence from work regarding cultivation theory (Morgan \& Shanahan, 1997; Romer, Jamieson, \& Aday, 2003), vividness (Snyder \& Rouse, 1995), the availability heuristic (Folkes, 1998; Pachur, Hertwig, \& Steinmann, 2012; Tversky \& Kahneman, 1973), agenda setting (Scheufele \& Tewksbury, 2007), and other work on media effects suggest that being exposed to terror-related news stories should increase one's fears of terror as well as the perceived risks of terror.

\section{H1: Exposure to a news story about terror will increase fears about} terror.

H2: Exposure to a news story about terror will increase perceptions of terror risks.

Media literacy may interact with the influence of news stories on fears about terror and perceptions of risk. People who understand that actors in the media select a biased sample of stories will be less influenced by these stories, mentally correcting for the unrepresentativeness of media stories.

H3: Media literacy will interact with exposure to terror news to influence fears about terror, with news about terror having a smaller effect as media literacy increases.

H4: Media literacy will interact with exposure to terror news to influence perceptions of terror risk, with news about terror having a smaller effect as media literacy increases.

Previous research showed that media literacy can have an effect on perception of media bias (Vraga et al., 2009) and perception and risk of terrorism after exposing to terror news (Comer, Furr, Beidas, Weiner, \& Kendall, 2008). In fact, journalists often blur out other side of opinions and fail to report the full picture of events (Bennett, 2015). Especially, in the case of news coverage of brutal events like crime, war, or terror, the event can be exaggerated or marginalized by the way of shaping news stories and sticking on sensationalism. Critical thinking about media representation can make people less susceptible to media messages (Gainer, 2010). Representation and reality, among media literacy framework, aligns with these ideas, and it is predicted that a person with a better understanding of representation and reality is less threatened by terror news than a person without it. 
Thus, focusing on representation and reality among media literacy framework is plausible in this research in order to measure a potential interaction effect.

\section{METHOD}

Participants. One hundred eighty-nine undergraduate participants were recruited from a communication department subject pool. The mean age was 20 years old, and $72 \%$ of participants were female, and $7 \%$ of the sample was AfricanAmerican.

Procedure. After reviewing informed consent documents, participants were randomly assigned to either a fear or a control condition. The stories used were actual news stories edited for length.

In the fear condition, participants read about deaths caused by the Boston Marathon bombing (Arsenault, 2013). This article graphically describes the scene of the attack and the aftermath, selected because it vividly describes a type of threat that continues to receive attention in media narratives (Combs \& Slovic, 1979; Darling-Hammond, 2016), and describes American victims with whom participants are likely to identify. Although the attack is likely familiar to many respondents, because the influence of media on threat perceptions is based on accessibility (Busselle \& Shrum, 2003; Busselle, 2001; Shrum, Wyer \& O'Guinn, 1998), the story should influence threat perceptions by making the threat of terrorism more accessible even to people who were already familiar with the terror attacks.

In the control condition, participants read a news story about the discovery of a new dinosaur (Kennedy, 2016). The control condition was designed to avoid any references to current threats and to be of equivalent length to provide a similar reading task across groups. Both the fear and control materials were edited for length from actual news stories and included a relevant image. The stories were presented with the logos of the original source to increase the realism of the stories include news stories from the Boston Globe and NPR.

Measures. Fear of Terror. After exposure to stimuli materials, participants completed a questionnaire. Participants indicated their level of fear of terrorism with three items. Scores ranged from 1 (not at all worried) to 4 (a great deal worried). For example, one of the items read, "How worried are you that... [t]here will be a terror attack in the United States in the next few weeks." The items were combined into a standardized additive scale $(\alpha=86)$.

Perceived Risk of Terror. Two items asking people to gauge the perceived likelihood of a) being a victim of a terror attack or b) knowing someone (other than themselves) who is the victim of a terror attack (ranked from 1="very unlikely" to $7=$ "very likely"). The items were combined into a standardized additive scale $(\alpha=$ .90). A third item, in which respondents ranked different causes of death, was excluded because some participants indicated (in an open-ended question soliciting feedback about the survey) that the software did not work for that question.

Media Literacy. Building on prior research, we created five Likert -type items to measure media literacy. In particular, the items gauged people's perceptions of the relationship of media representations to reality, and in particular 
the idea that media coverage represents a biased sample of events in the world (e.g. "The news media tend to cover events that are unusual"). The items were combined into a standardized additive scale $(\alpha=.75)$.

Media Trust. Media trust is a distinct concept from media literacy. People high in media trust may dismiss a media report out of hand because they believe the media to be inaccurate or biased. We created a measure of media trust to control for the influence of trust on media reports to control for the influence of media trust with a series of two Likert items (e.g. "The news media usually get the facts straight") and a multiple choice item, rating trust in the media. The items were combined into an standardized additive scale $(\alpha=.77)$.

Inferential reasoning. Participants' inferential reasoning ability was assessed with multiple choices about sampling knowledge and about scenarios describing the use of statistical techniques (Fong, Krantz \& Nisbett, 1986). The scenarios were designed to evaluate people's ability to apply concepts from sampling theory to real world events (Fong, Krantz \& Nisett, 1986; Jepson, Krantz, \& Nisbett, 1983; Watson \& Callingham, 2003).

A standardized additive scale was created out of 5 items, with higher scores indicating greater knowledge about inference. The reliability of the final score was $\alpha=.63$, which is relatively low for social science construct, although previous attempts to create scales measuring statistical knowledge have also been low (see, for example, Jepson, Krantz, \& Nisbett, 1983).

Perceived numerical competency. Participants were asked to rate their own ability to handle numerical problems such as calculating percentages and fractions. Prior work has shown self-reports on this scale to be valid indicators of actual numeracy (Fagerlin, Zikmund-Fisher, Ubel, Jankovic, Derry, \& Smith, 2007; Zikmund-Fisher, Smith, Ubel, Fagerlin, 2007). On a 5-point scale participants rated themselves on three items from "very good" to "very bad," with higher scores indicating a greater belief in their numerical competency. A standardized additive scale was created, with higher scores indicating greater self-reported ability with numbers $(\alpha=.79)$.

Need for cognition. Participants indicated their need for cognition (Cacioppo $\&$ Petty, 1982) with three items that assessed how much they enjoy contemplation, including: "The notion of thinking abstractly is appealing to me", "Thinking is not my idea of fun" and "I prefer my life to be filled with puzzles that I must solve". Participants rated their need for cognition on 7-point Likert-type items ranging from "strongly disagree" to "strongly agree." The items were combined into a standardized additive scale, with higher scores indicating greater need for cognition. The reliability of the scale was .68 .

\section{RESULTS}

The dependent variables in the regression analyses are measures for (a) fear of terror and (b) perceived likelihood of a terror attack. The regression models are estimated with ordinary least squares. Models were estimated with robust standard 
errors because a Breusch-Pagan/ Cook-Weisberg test for heteroscedasticity rejected the null hypothesis $(\mathrm{p}<.10)$ of constant variance.

The key independent variable is the indicator for treatment category (equals 1 for assignment to the story about a terror attack, 0 for the control story). All models were run with controls for media literacy, media trust, inferential knowledge, need for cognition, and numeracy self-ratings. An alternative specification adds controls for gender, age, age squared, and indicators for party identification (Democrat or Republican). The results are presented in Table 1.

\section{Table 1}

\section{Ordinary Least Squares Estimates of Exposure to Terrorism Story on Fears and Perceived Likelihood of Terror}

\begin{tabular}{ccccc} 
& Model 1 & Model 2 & Model 3 & Model 4 \\
\hline Terrorism Story & $\underline{\mathrm{B}(\mathrm{SE})}$ & $\underline{\mathrm{B}(\mathrm{SE})}$ & $\underline{\mathrm{B}(\mathrm{SE})}$ & $\underline{\mathrm{B}(\mathrm{SE})}$ \\
Media Literacy & $.64 *(.12)$ & $.65^{*}(.12)$ & & $.52^{*}(.13)$ \\
Media Trust & & $.07(.08)$ & $.53 *(.13)$ & $-.01(.10)$ \\
Inferential Reasoning & & $-.10(.07)$ & & $-.07(.09)$ \\
Need for Cognition & & $-.18(.11)$ & & $-.20(.12)$ \\
Numeracy & -0.0135 & & -0.0189 \\
Female & $.03(.08)$ & & $-.09(.09)$ \\
African American & & $.39 *(.12)$ & & $.02(.17)$ \\
Age & -0.144 & & $-.59(.29)$ \\
Age & & $-.10(.15)$ & & $-.04(.16)$ \\
& & $.00(.00)$ & & $.00(.00)$ \\
Constant & & & & $.66(2.0)$ \\
\hline $\mathrm{N}$ & $-.33(.09)$ & $.75(1.8)$ & $-.27(.08)$ & 182 \\
$\mathrm{R}^{2}$ & 183 & 182 & 183 & 0.17 \\
\hline
\end{tabular}

$*=\mathrm{p}<.05$, one-tailed. Robust SE's in parentheses.

The coefficient for the treatment variable in Model 1 represents the average treatment effect on the standardized measure of fear about terror. The coefficient is positive and statistically significant $(\mathrm{p}<.05$, one-tailed). Exposure to the treatment, on average, increases fear of terror by about two thirds of a standard deviation. The sign, magnitude, and statistical significance are unchanged with the addition of control variables (Model 2). Models 3 and 4 explore the influence of terror on rankings of terror as a cause of death. The coefficient for the terrorism treatment represents the average influence of exposure to the terrorism story on perceptions of the likelihood of a terror attack. The coefficient for Model $3(.53)$ is positive and statistically significant $(\mathrm{p}<.05$, one-tailed), and indicates that exposure to the terrorism story increased the perceived likelihood of a terror attack by about one 
half of a standard deviation. The coefficient in Model 4, with the addition of the control variables, is similar in sign, statistical significance, and magnitude. The results support $\mathrm{H} 1$ and $\mathrm{H} 2$ : exposure to news about terror increases fears and perceived likelihood of terror attacks.

Before moving on, it is instructive to consider the sign, magnitude of the coefficients for some of the control variables in Models 2 and 4 to consider the relationship between some of the control variables and concerns about terror. The coefficients for media literacy in Models 2 and 4 are small, positive, and not statistically significant, suggesting that there is no direct relationship of media literacy on fears about or perceived likelihood of terrorism. The coefficients for numeracy, and media trust all fall short of statistical significance ( $p>.05$, onetailed). The coefficients for inferential knowledge ( $\mathrm{p}=.05$, one-tailed) and need for cognition ( $\mathrm{p}<.05$, one-tailed), however, are negative and either approach or reach statistical significance, suggesting that some cognitive resources and dispositions are related to concerns about terror.

\section{Table 2}

Ordinary Least Squares Estimates of Interaction Effects of Media Literacy and Exposure to Terrorism Story

\begin{tabular}{ccc}
\hline & Model 5 & Model 6 \\
\hline Terrorism Story & $\underline{\mathrm{B}(\mathrm{SE})}$ & $\underline{\mathrm{B}(\mathrm{SE})}$ \\
Media Literacy & $-.13(.12)$ & $.52^{*}(.14)$ \\
Terrorism X Literacy & $.40 *(.16)$ & $-.07(.13)$ \\
Media Trust & $-.11(.08)$ & $-.07(.09)$ \\
Inferential Reasoning & $-.20(.11)$ & -0.0252 \\
Need for Cognition & $-.15(.08)$ & -0.0189 \\
Numeracy & $.02(.09)$ & $-.09(.09)$ \\
Female & $.38 *(.12)$ & $.02(.16)$ \\
African American & -0.162 & -0.1769 \\
Age & $-.04(.15)$ & $-.03(.16)$ \\
Age & $.00(.00)$ & $.00(.00)$ \\
& & \\
Constant & $.08(1.9)$ & $.46(2.1)$ \\
\hline $\mathrm{N}$ & 182 & 182 \\
$\mathrm{R}^{2}$ & 0.26 & 0.17 \\
\hline
\end{tabular}

$*=\mathrm{p}<.05$, one-tailed. Robust SE's in parentheses.

A second set of regression results, displayed in Table 2, is the same as those displayed in Table 1, with an added interaction term (terror treatment $X$ media literacy). The models include the full set of controls. The coefficient for the 
treatment variable represents the impact of the terror treatment on terror concerns for those with average levels of media literacy. The coefficients for the variable are statistically significant ( $\mathrm{p}<.05$, one-tailed) and positive. In other words, exposure to the terrorism story increased fears of terror among those with average levels of media literacy.

More relevant to $\mathrm{H} 3$ and $\mathrm{H} 4$, the coefficient of the interaction term reflects whether or not the terrorism treatment has different effects of people based on their skill in inferential reasoning. Model 5 explores the impact of the terrorism story on fear of terror attacks. The coefficient for the interaction term is statistically significant $(\mathrm{p}<.05$, one-tailed), but is positive, opposite the expected direction. That is, the influence of the terror story on fear of terror attacks increases with media literacy, opposite the hypothesized direction. Model 6 explores the impact of the terrorism story on the perceived likelihood of attacks. Again, the coefficient for the interaction term is not statistically significant in either model. The results do not support either $\mathrm{H} 3$ or $\mathrm{H} 4$ : there is no evidence of an interaction effect between terrorism coverage and media literacy on the outcomes explored.

\section{DISCUSSION}

In our online study, we found that media coverage of terror influences fear of terror and perceived likelihood of terror attacks. The results support a large body of research that demonstrates the impact of media on fears and risk perceptions (Morgan \& Shanahan, 1997). Two hypotheses in the current paper deal with the impact of exposure to a terror news story. The results show that being exposed to terror news increases participants' fear about terror, and their perceptions of terror risks. These findings align with theories such as cultivation theory (Morgan \& Shanahan, 1997; Romer, Jamieson, \& Aday, 2003), vividness (Snyder \& Rouse, 1995), the availability heuristic (Folkes, 1998; Pachur, Hertwig, \& Steinmann, 2012; Tversky \& Kahneman, 1973), and agenda setting (Scheufele \& Tewksbury, 2007). These theories and our study imply that news is influential in arousing fear about terror and perceptions of terror risks.

More original to the current study, we predicted that media literacy could mitigate the impact of terror coverage. In particular, we expected that the ability to critically examine media coverage would limit the impact of terror coverage on fears of terror. Two hypotheses posit the interaction effect of media literacy and media. However, we found no evidence that media literacy-in particular, literacy about media representations of reality- moderated the impact of terrorism news on fears of terror or perceptions of terror risk.

The results suggest that, while prior work has produced valid, reliable measures of media literacy, perhaps media literacy simply is not that important when faced with news coverage of threatening events. Scholars who developed the concept argue (reasonably, we initially thought) that people high in media literacy are better able to recognize that media coverage is not necessarily representative of reality (Ashley, Maksl, \& Craft, 2013; Arke \& Primack, 2009; Primack \& Hobbs, 2006). Specifically, people who realize that journalists and editors make choices 
about what to cover should understand that events covered in the news represent a biased sample of events in the real world. Media coverage therefore should not necessarily influence fears about and perceptions of the likelihood of terrorism among those high in media literacy. Our study showed that, at least with respect to the domain of terror coverage, this is not the case.

We found that the coefficients for the interaction terms in our regressions (media literacy $\mathrm{X}$ terror news) were small and not statistically significant. These effects were the same with both of our dependent variables (representing fears of terror and perceived likelihood of terror attacks) and with different regression specifications.

The results are somewhat confounding. The concept of media literacy is valid in that the concept is in line with efforts to teach students about media literacy (Potter, 2010). Our measures have face validity, based on prior efforts to develop measures of literacy about representation in the media (Primack \& Hobbs, 2006), and are reliable. Yet there is no evidence that media literacy enables people to resist the impact of scary media coverage on fears and risk perceptions, a central concern of decades of research on media effects (Morgan \& Shanahan, 1997). While more work on this topic remains to be done, in our view, this represents an important failure of media literacy. If the highly media literate are as vulnerable as everyone else to the effects of media coverage on fear and inflated risk perceptions, what, exactly, is the role of media literacy? Our results suggest that media literacy does not play any clear role in people's interpretation of news media coverage about terrorism.

One challenge of the current work is thinking about events in the world as a population, and media coverage as a sample of that population. Critically applying media literacy to stories of terror requires people to understand rudimentary concepts of sampling. However, prior work suggests that people struggle with mathematical concepts (Golbeck, Ahlers-Schmidt, Paschal, Dismuke, 2005). In addition, events in the world are not a population in the sense that people in the United States are a population that can be sampled. The fact that events in the world are not a "natural kind," or a concrete set of objects that are easy to imagine sampling, creates yet another barrier to applying critical thinking to media coverage (Gavanski \& Hui, 1992).

\section{CONCLUSION}

The results show that people with different levels of media literacy do not respond differently to print news stories about terrorism. This contradicted our predictions, based on theoretical expectations and prior literature about the nature of media literacy. Here we consider some of the limitations of the study, and in particular, the external validity of the current results.

First, we measured one component of media literacy, a multifaceted concept. While we selected the media component that we considered most relevant to concerns about drawing inferences from samples, representation and reality (Bennett, 2015; Gainer, 2010; Fürsich, 2010), perhaps other components are more 
important. Future research should explore other components of media literacy, including different components like authors and audience, messages and meanings (Primack \& Hobbs, 2006), or using completely different domains like recall, purpose, viewpoint, and technique (Arke \& Primack, 2009). Prior work has in fact shown that media literacy can influence perceptions of media bias (Vraga, Tully, Akin \& Rojas, 2012) and children's skepticism of advertisements (Eintraub, Kristine \& Johnson, 1997). Perhaps other topics are more responsive to media literacy education than concerns about terror.

A second set of concerns relates to the sample. The sample involved students in a Communication subject pool. Perhaps such students are relatively savvy about media consumption relative to the broader population. While there appeared to be considerable variability in the measure, a highly media literate sample would reflect a restriction of range in the media literacy variable, which could dampen the perceived effects. A similar test with a more heterogeneous sample could evaluate this hypothesis.

The nature of the stimulus could be another important factor in considering the generalizability of the results. The terror story selected was particularly vivid, involving a terror attack at the Boston Marathon, a popular yearly event, and resulting in the death and mutilation of multiple people. A photo in the story depicted a young boy killed by the bombing. Perhaps when faced with particularly emotional stories like this one, cognitive skills such as critical thinking about media, are not relevant. Affect, such as fearful responses to vivid stories about terror, have been shown to influence risk perceptions (Loewenstein, Weber, Hsee, \& Welch, 2001). Perhaps with other less vivid, but still important, stories about crime, terror and disasters, people higher in media literacy are better able to apply their skills in critical evaluation o the media. In addition, perhaps with especially vivid materials, people higher in media literacy may be better able to process this material, although it may not happen immediately.

In the fledgling field of media literacy, scholars have found success in conceptualizing and measuring media literacy. Efforts to influence media use through media literacy has encountered some successes, influencing perceptions of media bias and introducing a healthy skepticism about media advertisements. However, the current design shows some limitations of the concept of media literacy. Future work should explore whether media literacy education can influence the well-documented influence of media use on perceptions of a dangerous world.

\section{REFERENCES}

Ashley, S., Maksl, A., \& Craft, S. (2013). Developing a news media literacy scale. Journalism \& Mass Communication Educator, 68(1), 7-21.

Arke, E. T., \& Primack, B. A. (2009). Quantifying media literacy: Development, reliability, and validity of a new measure. Educational media international, 46(1), 53-65.

Arsenault, M. (2013. April 16). 3 killed in Marathon blasts. The Boston Globe. Retrieved from https://www.bostonglobe.com/metro/2013/04/15/three- 
killed-more-than-injured-marathonblast/QQOiYNU2n1vt1Xul3BXVsL/story.html

Bennett, W. (2015). News : the politics of illusion. Chicago: University Of Chicago Press.

Bier, M. C., Schmidt, S. J., Shields, D., Zwarun, L., Sherblom, S., Primack, B., Pulley, C. \& Rucker, B. (2013). School-based smoking prevention with media literacy: A pilot study. Journal of Media Literacy Education, 2(3), 1.

Busselle, R. W., \& Shrum, L. J. (2003). Media exposure and exemplar accessibility. Media Psychology, 5(3), 255-282.

Combs, B., \& Slovic, P. (1979). Newspaper coverage of causes of death. Journalism and Mass Communication Quarterly, 56, 837.

Comer, J. S., Furr, J. M., Beidas, R. S., Weiner, C. L., \& Kendall, P. C. (2008). Children and terrorism-related news: training parents in Coping and Media Literacy. Journal of consulting and clinical psychology, 76(4), 568.

Gainer, J. S. (2010). Critical media literacy in middle school: Exploring the politics of representation. Journal of Adolescent \& Adult Literacy, 53(5), 364-373.

Darling-Hammond, S. (2016, January 13) Lives fit for print: Exposing media bias in coverage of terrorism. The Nation. Retrieved from https://www.thenation.com/article/lives-fit-for-print-exposing-media-biasin-coverage-of-terrorism/.

Eintraub, E. W., Kristine, A., \& Johnson, K. (1997). Effects of general and alcoholspecific media literacy training on children's decision making about alcohol. Journal of health communication, 2(1), 17-42.

Fagerlin, A., Zikmund-Fisher, B. J., Ubel, P. A., Jankovic, A., Derry, H. A., \& Smith, D. M. (2007). Measuring numeracy without a math test: development of the Subjective Numeracy Scale. Medical Decision Making, 27(5), 672680.

Folkes, V. S. (1988). The availability heuristic and perceived risk. Journal of Consumer research, 15(1), 13-23.

Fong, G. T., Krantz, D. H., \& Nisbett, R. E. (1986). The effects of statistical training on thinking about everyday problems. Cognitive psychology, 18(3), 253-292.

Fürsich, E. (2010). Media and the representation of Others. International Social Science Journal, 61(199), 113-130.

Gallup (March 23, 2016). Worry about terror attacks in U.S. High, but not top concern. Retrieved from http://www.gallup.com/poll/190253/worry-terrorattacks-high-not-topconcern.aspx?g_source=terror\%20worry\&g_medium $=$ search \&g_campaign $=$ $\underline{\text { tiles }}$

Gavanski, I., \& Hui, C. (1992). Natural sample spaces and uncertain belief. Journal of Personality and Social Psychology, 63(5), 766.

Gerbner, G., \& Gross, L. (1976). Living with television: The violence profile. Journal of Communication, 26(2), 172-194. 
Golbeck, A. L., Ahlers-Schmidt, C. R., Paschal, A. M., \& Dismuke, S. E. (2005). A definition and operational framework for health numeracy. American journal of preventive medicine, 29(4), 375-376.

Jepson, C., Krantz, D. H., \& Nisbett, R. E. (1983). Inductive reasoning: Competence or skill? Behavioral and Brain Sciences, 6(3), 494-501.

Kahneman, D., \& Tversky, A. (1981). The simulation heuristic (No. TR-5). Stanford University, CA: Department of Psychology.

Kellner, D., \& Share, J. (2005). Toward critical media literacy: Core concepts, debates, organizations, and policy. Discourse: studies in the cultural politics of education, 26(3), 369-386.

Kennedy, M. (2016, March 14). Newly discovered dinosaur helps explain rise of tyrannosaurs. NPR. Retrieved from http://www.npr.org/sections/thetwoway/2016/03/14/470398526/newly-discovered-dinosaur-helps-explain-riseof-tyrannosaurs

Livingstone, S. (2004). Media literacy and the challenge of new information and communication technologies. The Communication Review, 7(1), 3-14.

Loewenstein, G. F., Weber, E. U., Hsee, C. K., \& Welch, N. (2001). Risk as feelings. Psychological bulletin, 127(2), 267.

Nellis, A. M., \& Savage, J. (2012). Does watching the news affect fear of terrorism? The importance of media exposure on terrorism fear. Crime \& Delinquency, 58(5), 748-768.

Morgan, M., \& Shanahan, J. (1997). Cultivation research: An appraisal and metaanalysis. In B. R. Burleson (Ed.), Communication Yearbook 20 (pp. 1-45). Thousand Oaks, CA: Sage.

Pachur, T., Hertwig, R., \& Steinmann, F. (2012). How do people judge risks: availability heuristic, affect heuristic, or both?. Journal of Experimental Psychology: Applied, 18, 314.

Potter, W. J. (2010). The state of media literacy. Journal of Broadcasting \& Electronic Media, 54(4), 675-696.

Romer, D., Jamieson, K. H., \& Aday, S. (2003). Television news and the cultivation of fear of crime. Journal of communication, 53(1), 88-104.

Scharrer, E. (2006). " I noticed more violence:" The effects of a media literacy program on critical attitudes toward media violence. Journal of Mass Media Ethics, 21(1), 69-86.

Scheufele, D. A., \& Tewksbury, D. (2007). Framing, agenda setting, and priming: The evolution of three media effects models. Journal of Communication, 57(1), 9-20.

Shrum, L. J., Wyer, R. S., \& O'Guinn, T. C. (1998). The effects of television consumption on social perceptions: The use of priming procedures to investigate psychological processes. Journal of Consumer Research, 24(4), 447-458.

Snyder, L. B., \& Rouse, R. A. (1995). The media can have more than an impersonal impact: The case of AIDS risk perceptions and behavior. Health Communication, 7(2), 125-145. 
Thoman E., \& Jolls, T. (2005). CML media kit. The center for media literacy. Retrieved from http://www.medialit.org/sites/default/files/01_MLKorientation.pdf

Tversky, A., \& Kahneman, D. (1973). Availability: A heuristic for judging frequency and probability. Cognitive psychology, 5, 207-232.

U.S. State Department. (2015). Country reports on terrorism 2015, Retrieved from https://www.state.gov/j/ct/rls/crt/2015/257526.htm

Vraga, E., Tully, M., Akin, H., \& Rojas, H. (2012). Modifying perceptions of hostility and credibility of news coverage of an environmental controversy through media literacy. Journalism, 1464884912455906.

Vraga, E. K., \& Tully, M. (2015). Media literacy messages and hostile media perceptions: Processing of nonpartisan versus partisan political information. Mass Communication and Society, 18(4), 422-448.

Zikmund-Fisher, B. J., Smith, D. M., Ubel, P. A., \& Fagerlin, A. (2007). Validation of the Subjective Numeracy Scale: effects of low numeracy on comprehension of risk communications and utility elicitations. Medical Decision Making.Zillmann, D., \& Brosius, H. B. (2012). Exemplification in communication: The influence of case reports on the perception of issues. New York: Routledge. 